\title{
The main directions of education development in the conditions of digitalization
}

\author{
Alexandra Ulzytueva*, Nina Vinogradova, and Oyuna Ulzutueva
}

Transbaikal State University, 672039, Chita, Russia

\begin{abstract}
The article discusses the urgent problem of the education system - the preschool education development in the context of digitalization. The solution of this problem is facilitated by the creation of an information and educational environment, as well as the use of information and communication tools in communication, construction, play and other types of productive creative child activity. The authors of the article presented in detail four directions of the preschool education development in the context of digitalization: the creation of an information and educational environment (IEE) that meets the requirements of the harmonious holistic development of preschool children; ICT software assuring electromagnetic safety; introduction of new information technologies; formation of information competence in subjects of educational relations; and also gave an example of the use of these directions in the preschool educational institution (PEI) and the developed methodological sequence in the implementation of program content. The use of telecommunications, Intranet and Internet networks, telephone communications, etc. for the exchange of information brings variety to the joint activities of children and teachers. The authors of the article note that for the preschool education development in the context of digitalization, it is necessary to create in PEI a regulatory and legal framework, psychological and pedagogical conditions, a material and technical base, electronic educational resources, a criterion-diagnostic base, as well as to organize work with children, parents and teachers.
\end{abstract}

\section{Introduction}

In modern society, the level of digitalization of all spheres of human life is naturally increasing. Considering digitalization as a tool for social transformation of society, sociologists identify the main cultural trends that will be provided by this toolkit. Ya.N. Peters defined these trends as the imposition of a single culture of consumption of goods on all societies, multilevel hybridization of local and global life practices, syncretism of religions and the fusion of languages (creolization) [1], mixing of the population, the imposition of modern mass culture; polarization of ethnic groups, "leading to manifestations of multi-level conflicts, from global to local" [2]. Psychologists and educators note that the main problem of the future information society will not be the solution of technocratic problems, but the psychological prevention of the axiological collapse of human life, to which the

* Corresponding author: alendra29@mail.ru 
implementation of the basic cultural trends in the development of mankind as a whole leads [3].

Awareness of the inevitability of improving digitalization means and their use in the educational environment actualizes the issue of transforming of the content, forms, methods of teaching and upbringing into means of holistic development of children, harmonious to the rhythms of their physiological and psychological health [4]. The question of how to digitize education is especially acute in preschool education. The researchers note that the implementation of digital technologies in preschool education is fraught with a number of difficulties: modern preschool children are more emotionally developed than previously thought. Based on this, Lubi and his colleagues have documented clinical depression of children under 3 years of age [5]. Uncontrolled use of educational portals by preschoolers leads to an increase in anxiety disorders. Researchers have identified links between "problematic use of learning portals with neuroticism, unconsciousness, psychopathy, and mental disorder" [6]. Unformed digital competence of preschool teachers can lead to an increase in the aggressiveness of the information environment of preschool education. This causes a narrowing of the social potential of their general development. Social intelligence will naturally degrade and distort many moral and ethical norms of behavior. The need for interpersonal communication, which is not realized in childhood, can act as a significant unfavorable factor in the development of the psyche in more mature ages and "increase a person's reactivity to subsequent stressors" [7]. This will lead to the manifestation of numerous social pathologies. Preschoolers easily succumb to manipulative technologies based on keeping attention only on external attributes, and not on analyzing the logic of the characters' behavior. Imprinting as a special form of imprinting, characteristic of preschoolers, has irreversible consequences for further perception of the world and can become a source of phobias of different genesis [8].

An appeal to strategic and regulatory documents shows that the introduction of digital technologies is becoming one of the urgent problems in the Russian education system. Thus, the national project "Education" sets out the task of creating a modern and safe digital educational environment by 2024 , ensuring high quality and accessibility of all types and levels of education [9].

The Federal Law "On Education in the Russian Federation" states that "in the implementation of educational programs, various educational technologies are used, including distance educational technologies, e-learning" [10]. The Order of the Ministry of Education of the Russian Federation of August 23, 2017 No. 816 "On approval of the Procedure for the use of e-learning, distance learning technologies by organizations engaged in educational activities in the implementation of educational programs" states that "organizations have the right to implement educational programs using exclusively elearning, distance learning technologies, organizing classes in the form of online courses that provide for students, regardless of their location and the organization in which they master the educational program, the achievement and assessment of learning outcomes by organizing educational activities in an electronic information and educational environment, to which open access is provided through information and telecommunication network Internet".

The sanitary and epidemiological requirements for the structure, content and organization of the preschool educational institution's working regime contain requirements for personal computers and the organization of work when conducting classes for children using computer technology.

The process of digitalization of the education system is dictated not only at the state level, but also at the public level. It is obvious that educational platforms of online education are 
already being actively created at the university and in schools, distance education is being introduced, while many questions about the trends and mechanisms of development of preschool education in the context of digitalization still remain relevant.

Digitalization of the educational process is a social situation of the development of participants in educational relations, involving the use of digital technologies [11]. Digitalization creates conditions for the exchange of experience and knowledge, which allows to make more effective decisions in various areas. In this article, we will consider four directions for the development of preschool education in the context of digitalization:

- creation of the information and educational environment (IEE);

- ICT software;

- introduction of new information technologies;

- information competence formation.

Digitalization of preschool education includes the creation of a single information educational space for preschool education. PEI teachers have the opportunity to widely introduce new methodological developments into pedagogical practice aimed at intensifying and implementing innovative ideas of the educational process [12].

\section{Materials and Methods}

Let's take a closer look at all areas of development of preschool education in the context of digitalization:

The first direction is a creating an information and educational environment (IEE). The efficiency of the informatization process directly depends on the efficiency of the processes of creating and using an information resource, i.e. the entire information potential of society. The educational environment is the totality of all the opportunities for learning, education and personal development. The information environment is the world of information around a person, the world of his information activity. The information and educational environment of pre-school education (PEI IEE) is an open pedagogical system aimed at the formation of a creative, intellectual and socially developed personality, formed on the basis of a variety of information educational resources, modern information and communication tools and pedagogical technologies [13].

The main components of the PEI IEE are: a complex of information educational resources, including digital educational resources; a set of technological means of ICT: computers, other ICT equipment, communication channels; a system of modern pedagogical technologies. The PEI IEE provides information and methodological support of educational activities; planning of educational activities and their resource provision; monitoring and recording of the progress and results of educational activities; monitoring of the pupils' health; modern procedures for creating, searching, collecting, analyzing, processing, storing and presenting information; remote interaction of all participants in educational relations (children, teachers, parents, educational authorities, (the public)), including within the framework of distance education; remote interaction of an educational organization with other social organizations: cultural institutions, health care, sports, leisure, employment services, life safety.

The second direction is ICT software tools. It is obvious that one of the main aspects of the information and communication technologies are information and communication means, which include software, hardware and hardware and technical means and devices that operate on the basis of microprocessor, computer technology, as well as modern means and systems for transmitting information, information exchange, providing operations for the 
collection, production, accumulation, storage, processing, transmission of information and the ability to access information resources of local and global computer networks [14].

In the literature, there are hardware and software types of ICT tools. ICT hardware includes a computer, printer, scanner, camera, video camera, audio and video recorder, etc., and software - electronic textbooks, simulators, test environments, information sites, Internet search engines, etc.). In the context of digitalization, the creation of software tools by preschool teachers that will contribute to the development of children's mental qualities (attention, memory, imagination, thinking) becomes relevant. The use of electronic educational resources developed in accordance with the program content, age and individual characteristics of children, contributes to the achievement of such targets as the development of independence and initiative of children [15].

The third direction is the introduction of new information technologies. $O$. $D$. Ochirova developed a technology for the implementation of program content through ICT, in which the study of each new topic takes place in the following methodological sequence, "step-by-step" concept:

Step1 -educational activities using an electronic manual, computer games, workbook, resource cards;

Step 2-walk through the virtual mini-museum;

Step 3-productive children's activity on the computer; [16].

Step 4 - monitoring the knowledge of preschool children using didactic computer games

O. D. Ochirova also proposes to organizeg with such a sequence, work through ICT is productive, provided that personnel, material and technical conditions are created, interaction with parents, the creation of electronic educational resources, and the requirements of the SanPiN are taken into account. It should be noted that the use of ICTs does not replace traditional forms and means of education and development of children, but complements and replenishes them.

O. D. Ochirova also suggests organizing all work using a computer in 3 stages (precomputer, computer and post-computer), regardless of where it is used: whether in organized educational activities or in educational activities in regime moments (children's activities, holidays, folk games, etc.). At the same time, she notes that a preschool child can be at the computer without a break from 5 to 10 minutes, so the use of ICT is allowed only as one of the stages of work in any type of activity [17]. Therefore, compliance with the rules of the child's work at the computer is an important requirement for the use of ICT during educational activities.

Table 1. Stages of the use of ICT in organized educational activities.

\begin{tabular}{|l|l|}
\hline \multicolumn{2}{|c|}{ Pre-computer stage } \\
\hline Use of interactive demonstration material & $\begin{array}{l}\text { Introductory work of the child with a } \\
\text { computer, with electronic educational } \\
\text { resources }\end{array}$ \\
\hline \multicolumn{2}{|c|}{ Computer stage } \\
\hline $\begin{array}{l}\text { Children's work with the electronic manual } \\
\text { and in workbooks }\end{array}$ & $\begin{array}{l}\text { Independent work of children on the } \\
\text { computer }\end{array}$ \\
\hline \multicolumn{2}{|c|}{ Post computer stage } \\
\hline $\begin{array}{l}\text { Summing up the work with the help of didactic } \\
\text { games and tasks }\end{array}$ & Reflection \\
\hline
\end{tabular}

So, during the educational activities using ICT at the pre-computer stage, teachers use interactive demonstration material, which motivates and attracts the attention of children; at 
the computer stage, they work with an electronic manual and in workbooks; at the postcomputer stage, the work is summarized.

The forth direction is the formation of information competence. There are different points of view on the problem of developing competencies in preschool children. The difference in approaches is due, obviously, to the fact that in the Federal State Educational Standards targets that do not include competencies are not specified. However, some publications highlight the key competencies of preschool children $[18,16]$. In our opinion, this approach is productive, and we adhere to the position that preschool age is sensitive for the development of individual social competencies, including information competence.

O. D. Ochirova developed criteria for identifying the formation of information competence in older preschoolers in three components (parameters):

The indicators of the cognitive component include: the ability to understand the need for a particular information for their activities; to be aware of the variety of information sources, to navigate in them, to identify the most meaningful and effective in the target setting; to be aware of the questions' importance.

The motivational component characterizes such indicators as: shows initiative, asking detailed, logically and thematically based questions on the topic of his interest; aligns them into a logical chain; shows cognitive interest; is interested in the possibilities of searching for information from various sources, even after explaining and showing an adult during joint activities; shows the need to assess the need for this or that information for their activities, achieving goals.

The behavioral component includes: the ability to navigate in some sources of information (books, art objects, toys, a story of a peer, an adult, television, computer, DVD movies, etc.); the ability to draw conclusions from the information received; the ability to ask questions on a topic of interest; the ability to obtain information using some sources; the ability to assess social habits related to health, consumption and the environment [16].

These criteria allow us to analyze and gradually trace the dynamics of the formation of information competence and at each stage to notice and overcome certain difficulties and problems in time.

At the same time, it is more difficult, in our opinion, to identify the formation of information competence in pre-school teachers. The 2020 has exacerbated the problem of forming information competence of preschool teachers, who were asked to organize educational activities in a remote format. Observations and conversations with teachers show that computer skills are not the evidence that the pedagogical community of preschool education is ready to solve the problems of organizing educational activities online with the use of distance learning tools.

\section{Results}

The proposed directions were tested in the course of experimental training, which was carried out for 18 weeks in the senior age group of the MDOU "Mogoytuy kindergarten "Balig", which is attended by 25 children. The training was carried out using the proposed technology in the implementation of the variable part of the basic educational program (BEP). This part was focused on introducing children to the regional culture through the use of ICT.

IEE was created in PEI, i.e. a mobile computer cabinet with Internet access and a license agreement was purchased, a single databank of parents receiving distance services was collected, the up-to-date information on distance learning was posted on the PEI website, online consultations, as well as teachers' blogs that provide virtual advice, broadcasting of 
advanced teaching experience, discussions and forums on the problems of distance learning have been functioning.

To organize remote interaction of all participants in educational relations, new positions, such as dispatcher, tutor, consultant were added to the staffing of the preschool educational institution; the tariff list was changed, job descriptions were developed. In addition to the functional responsibilities of the manager, the organization of the material and technical equipment of the distance education process, the general control of the activities of specialists within the framework of the implementation of the "roadmap" were included. The methodologist assists teachers and parents in choosing the form of education and training, as well as improving the qualifications of teachers and parents of children in organizing distance education. Educators, in addition to helping parents with distance learning and child-rearing, additionally maintain personal pages and blogs on the PEI website. The dispatcher provides guidance and control over the activity, coordination of remote interaction (registration of parents' applications, uniting parents into groups at their requests, coordinating the activities of groups, scheduling, specialists' appointing). The consultant organizes methodological support for the teachers' and specialists' activities; establishes feedback with parents through remote technologies; conducts methodological support of teachers; assists in drawing up an individual educational route, guidelines for working with parents of children. The tutor provides parents with advisory and methodological assistance in the upbringing, socialization and development of children, including children with disabilities.

The remote form of BEP implementation involves online lectures, remote consultations, webinars, video conferencing, discussion platforms, parent clubs, remote consulting rooms for parents, open online and offline events for parents, remote observation "aquariums", etc. Teachers create electronic ideas banks are organized by parental universities of childhood.

In our opinion, it is advisable to use ICT technologies in the educational activities of preschoolers in the process of implementing both the invariant and variable parts of the preschool education program. The implementation of all five educational areas of PEI BEP creates opportunities for digitalization. So, in the implementation of the educational area "Social and communicative development", issues of safety in everyday life, society, nature, the formation of ideas about good and evil, the acquaintance of children with the actions of people can be carried out through ICT. Currently, there are a sufficient number of video films, computer programs that contribute to the solution of the listed tasks. Acquaintance with the culture and traditions of one's own and other ethnic groups is an important task of the social and communicative development of children. The variable part is focused on familiarizing children with regional culture. Introducing preschoolers to the culture of different peoples through ICT is possible if children are interested in this process, if the best examples of world and regional culture (architecture, painting, music, etc.), accessible to children's perception and understanding, are translated into an electronic version, and virtual museums are created.

Here is an example of familiarizing with the regional culture through the electronic manual to the program "My native land", which includes four sections: local history, art, everyday culture, traditions. The manual contains diverse material about the region, selected and systematized in accordance with the age characteristics of children and containing interactive in the form of games and tasks for independent activity and reflection. Thanks to the convenient intuitive interface, soundtrack, colorful design, the manual can be used by preschool children who have the initial computer skills. While working in the virtual museum "My native land" created by the teachers of the PEI, a child with the help of ICT can choose a place and hear an interesting story, watch video and thus get acquainted with the sights of his native land. 
Educational activities using such ICT tools as a projector, computer, interactive board are aimed at personal development, the formation of children's competencies. The prerequisites for introducing preschoolers to regional culture are being created. ICT can be used both to assess the formation of a child's competencies and to plan activities and record the results of teachers and children.

Productive activity in the context of preschool education digitalization involves the independent work of older preschoolers on a computer using, for example, Power Point and SMART Board graphic editors.

Project activities with the use of ICT may have a different nature. For example, children together with their parents create a presentation on a traditional birthday celebration in the family. In kindergarten, teachers with children make up a fairy tale in an interactive version, for which they use maps-pictograms, pictures, and animations. An important component of the described process is reflection with the help of computer games.

At the end of the experiment, a comparative analysis of the results of the control and experimental groups was carried out. The control group was formed on the basis of the Mogoytuy kindergarten "Kolokolchik". 50 children participated in the control and comparative cross-section to identify the success of the components of information competence in preschool children.

Table 2. Success rate of components of information competence in preschool children.

\begin{tabular}{|c|c|c|c|c|c|}
\hline \multirow[t]{2}{*}{ № } & \multirow{2}{*}{$\begin{array}{c}\begin{array}{c}\text { Components of information } \\
\text { competence }\end{array} \\
\end{array}$} & \multicolumn{2}{|c|}{ Experimental group } & \multicolumn{2}{|c|}{ Control group } \\
\hline & & Before & After & Before & After \\
\hline 1 & $\begin{array}{l}\text { The ability to solve a problem } \\
\text { situation using different sources of } \\
\text { information. }\end{array}$ & 3 & 84 & 4 & 24 \\
\hline 2 & $\begin{array}{l}\text { The ability to understand the need } \\
\text { for information for their activities. }\end{array}$ & 5 & 80 & 4 & 15 \\
\hline 3 & $\begin{array}{l}\text { The ability to generalize the } \\
\text { information received. }\end{array}$ & 5 & 76 & 6 & 18 \\
\hline 4 & $\begin{array}{l}\text { The ability to independently use a } \\
\text { computer to obtain information. }\end{array}$ & 3 & 78 & 3 & 7 \\
\hline 5 & $\begin{array}{l}\text { The ability to use the media to get } \\
\text { information. }\end{array}$ & 4 & 61 & 3 & 15 \\
\hline 6 & $\begin{array}{l}\text { The ability to use the Internet to } \\
\text { obtain information. }\end{array}$ & 0 & 58 & 0 & 0 \\
\hline
\end{tabular}

Thus, it is no coincidence that we turned to solving the problem of familiarizing older preschoolers with regional culture as an example. This example demonstrates the importance of selecting specialized material that can be digitized. It seems that an appeal to any educational field in accordance with the calendar-thematic planning will make it possible to isolate the modules of the program material, which, with a creative and competent approach, teachers can digitize and include in educational activities. So, the theme "Development of temporal and spatial representations of children" (educational area "Cognitive development") is relevant throughout preschool childhood. Methodologically competent teachers have the opportunity to deepen and expand children's knowledge about time and space and the ability to navigate them through ICT. In this case, computer games, electronic workbooks, resource cards, a virtual museum, etc. can be used in accordance with the age characteristics of children.

\section{Discussion}


This article describes the approved directions of preschool education development in the context of digitalization, which includes the creation of an IEE and the information and communication educational space of pre-school children, the use of ICT in the educational activities of preschool children in the classroom, in the process of creating educational situations, in project activities and in regime moments, which is dictated by the main educational program of PEI in the process of implementing its invariant and variable parts.

The digitalization of preschool education has become particularly important in the context of the pandemic in the organization of distance education of preschool children and the need to improve the psychological and pedagogical parents' culture. The low level of readiness of the preschool education system for the implementation of BEP in the distance format should be noted. In our opinion, the time dictates us a new functional responsibility of teachers, which implies the formation of skills to create electronic educational resources, create and maintain blogs focused on interaction with the professional community, parents and children.

In our opinion, the digitalization of preschool education can play an important role in making managerial decisions at both the federal and regional, municipal levels. Obviously, in the conditions of digitalization and with the introduction of distance learning, changes and additions are made to the regulatory documents of kindergarten. The administration and teachers of the preschool educational organization are developing local acts, which include: "Regulations of the organization of distance learning," "Regulations of the use of e-learning, remote educational technologies in the implementation of the main general education program," "Regulations of the application of e-learning in the preschool educational organization, which carries out educational activities in the implementation of the main general education program" and others. The head of the kindergarten issues orders "On approval of the schedule of classes using remote educational technologies," "On the appointment of those responsible for monitoring the receipt of e-learning by students using remote technologies."

Within the framework of educational activities, a "Roadmap for the transition to distance learning" is being developed in a preschool educational organization, changes and additions are being made to the Development Program; in the Basic Educational Program, in the Annual Plan. We list from the Roadmap some events that are being held in a preschool educational organization in connection with the transition to distance learning.

1. Preparation of normative documentation on the organization of distance education, including the appointment of persons responsible for the organization of distance education; for informing participants in educational relations.

2. Monitoring of technical readiness of the organization.

3. Monitoring of the level of information and communication competence of teachers.

4. Analysis of the need of parents (legal representatives) for the organization of distance education.

5. Organization of further training courses for teachers.

6. Conduct a cycle of training events for teachers.

7. Creation of the section "Distance Education" on the website of the preschool educational organization.

8. Drawing up of a schedule, of departure schemes.

9. Approval of local acts at the level of preschool educational organization.

10. Participation in methodological meetings, online seminars, webinars on working with digital tools, the use of remote technologies, as well as the exchange of productive work experience with the help of the most advanced colleagues in the team.

11. Check the availability of the necessary gadgets for the parents of the pupils (computers, tablets, laptops, phones, their technical capabilities) (this issue should be agreed with parents). 
12. Organization of awareness-raising among parents by telephone hotline for parents on the problems of education using electronic and remote technologies.

13. Provision of technical facilities for the organization of distance learning for teachers.

14. Introduction of changes to teachers' work programs in terms of thematic planning, forms of distance learning, forms of feedback, links to used electronic educational resources.

15. Carrying out explanatory work with parents (legal representatives) on observance of the day, classes and rest regime, observance of personal hygiene.

16. Conduct a cycle of classes to overcome psychological barriers for parents in the organization of distance education.

17. Creation of electronic catalogue of educational events and others.

Digitalization of preschool education contributes to decision such problems as organization of network of a preschool educational organization to provide advice to teachers and parents, psychological and pedagogical support to families with children with disabilities and disabled people receiving preschool education in the family.

Thus, in the conditions of digitalization, as well as the forced transition to distance learning, the administration and teachers of the preschool educational organization need to improve the regulatory framework, including the development of local regulatory acts regulating the activities of pedagogical workers, the provision of educational services, as well as when implementing the Basic educational program, transfer the usual group activities to online format.

\section{Conclusion}

The inevitability of objective changes in the forms of social communication in the near future implies a natural change in the attitude to information, which must be formed in preschool age. The accumulation of large volumes of information makes new demands on preschool education specialists in terms of the semantic interpretation of information flows, their transformation into mechanisms for the harmonious development of the child's personality. The process of informatization in the preschool education system includes the following psychological and pedagogical conditions: the formation of the information competence of teachers, the availability of hardware and software, compliance with sanitary and epidemiological standards, the improvement of the information culture of parents, working with parents. Of course, the use of ICT gives a special specificity to the organization of various forms and types of activities with children, contributes to increasing interest in learning, its effectiveness, and develops the child's information competence. Modern PEI has many tools and opportunities for implementing information policy, in building models of interaction, implemented on the basis of ICT. At the same time, in the process of digitalization, special attention should be paid to the main directions of the development of preschool education, which are associated with the existence of an information and communication educational space and a modern infrastructure of a preschool organization, where productive interaction of subjects of educational relations takes place, in the process of which social experience is transmitted, knowledge is acquired, skills are acquired, information competencies are formed. Our proposed directions for the development of preschool education in the context of digitalization can be applied in all preschool educational institutions of the Russian education system, since they expand the educational space of the organization and allow to attract new resources of organizations for the implementation of consumers' and customers' requests, and for compliance with the Federal State Educational Standards of preschool education. 


\section{References}

1. J.N. Pieterse, Der Melange-Effekt (in: Beck U. Hg. Perspektiven der Weltgesellschaft, Frankfurt, 1998)

2. S. Huntington, The Clash of Civilizations (AST Publishers, Moscow, 2014)

3. W.J. Pelgrum, \& B.D. Doornekamp, Indicators on ICT in primary and secondary education (IIPSE) (Report commissioned by the Directorate General Education and Culture (IIPSE: EACEA-2007-3278/001-001). Brussels, Belgium, European Commission, 2009)

4. N.V. Dneprovskaya, Statistics and Economics 15(4), 16-28 (2018)

5. D. Llberia, Eur child adolescntry 30 (18) (10), 597-604 (2009)

6. F. Pettersson, Educ Inf Technol 23, 1005-1021 (2018) doi.org/10.1007/s10639-0179649-3.

7. S.O. Sukhotin, Organizational and legal bases of use of information technologies in the educational sphere, PhD Thesis, (MSJA, Moscow, 2014).

8. Yu.A. Lapteva, Psychological and pedagogical support for the emotional development of a child at different stages of preschool childhood, abstract of the dissertation for the degree of Candidate of Psychological Sciences (FSBEI HE "Kemerov State University", Kemerovo, 2017)

9. Passport of the national project "Education". https://minobrnauki.gov.ru/files/NP_Obrazovanie.htm, last accessed 2021/02/28.

10. Federal Law "On Education in the Russian Federation" 29.12.2012 № 273- Federal Law (2012) http://www.consultant.ru/document/cons_doc_LAW_140174/.

11. R.M. Safuanov, M.Yu Lehmus, E.A. Kolganov, Bulletin of USSTU, Science, education, economics. Series: Economics 2(28), 108-113 (2019)

12. D.V. Budantsev, Young scientist 27 (317), 120-127 (2020)

13. T.S. Komarova, I.I. Komarova, A.V. Tulikov and others, Information and communication technologies in preschool education (Mosaic synthesis, Moscow, 2011)

14. S.V. Guryev, Information computer technologies in physical education of preschoolers: methodology, theory, practice (RSPPU Publishing house, Yekaterinburg, 2008)

15. O.D. Ochirova, L.A. Shamanova, Formation of information and communication competence among teachers of preschool educational institution in Pedagogy: traditions and innovations, proceedings of the III International Scientific Conference, Chelyabinsk. 60-62, (2013)

16. O.D. Ochirova, Introduction of preschoolers to regional culture through information and communication technologies, PhD Thesis, (FSBEI HE "Transbaikal State University, Chita, 2011)

17. M.V. Hrapataya, Siberian Pedagogical Journal 9, 248-254 (2008)

18. D.A. Ivanov, Competence and competence approach in modern education (Chistyye prudy, Moscow, 2007) 